deprecated. I think entomologists might be more generous to one another. For my own part I would gladly pay handsomely in specimens to anyone who would name for me what I send, but I do not like parting with unique specimens. I collect only Manitoba insects, and have several species of which I have only seen single examples during the seventeen years I have been in the country. I have them annexed by some specialist. What then? I might, having taken the species, replace it by specimens from Nevada or Colorado, let us say. But they would not be Manitoba specimens, and very likely would present certain minor differences. All thanks and credit being given to those who, through greater advantages and opportunities, have acquired a knowledge which it is impossible for many of their brethren who are less favourably situated to gain, and impart that knowledge, but they exact too heavy a price for it, and by so doing, instead of encouraging the study of entomology, confine it within narrow limits by their action.

E. Firmstone Heath, Cartwright, Manitoba.

\title{
TRYPETA SOLIDAGINIS
}

BY M.RS. A. O. SNYDER, BELVIDERE, ILLINOIS.

A year ago last autumn, while rambling about the fields, we took especial notice of the galls upon the golden-rod. We saw that there were two kinds, the elongated and the round. We knew that from the former came a tiny moth, well-known to us, and from the latter a fly with which we were not familiar, or, if familiar, not known to come from this gall. The elongated galls were all empty, but the round ones we found upon examination contained each a small white grub. We gathered a quantity of the galls and placed them in a jelly glass on the writing table where they would be constantly before us for observation.

On the following twenty-first of April we noticed something peculiar about one of the galls. There was a movement at one little spot that soon looked like a tiny drop of water. We were on the alert instantly, and with microscopes in hand awaited developments. Upon closer investigation the "drop of water" looked more like a membranous bubble (ptilinum, I think is the correct term for this sac-like organ). With the naked eye it could be seen to expand and relax, and upon it were observed tiny drops of water or some liquid substance, - sweat drops as we shall call them.

The following is a minute description (for an amateur) of the emergence of the fly as seen through a hand Iens. In the first place 
there seemed to be a depression and ridge like the arcs of a great circle cutting each other at right angles and dividing the sac into quarters. The "sweat drops" stood out upon the ptilinum like little beads as it expanded and relaxed gently.

Suddenly the ptilinum apparently withdrew into the aperture of the gall, being almost out of sight, and then it as suddenly swelled out; at the same time there was a change in the position of the "sweat drops," and they were larger than before.

After this great relaxation and emergence the fly came out rapidly until the eyes were visible. The ptilinum extended far out above the eyes, overshadowing them. The appearance of the visible part of the fly at this period reminded one strongly of a back view of a head that is bald, the eyes of the fly taking the place of the ears. Under the magnifier the eyes were distinctly purplish.

After the head and part of the body were out of the gall the selaxations of the sac were shown by depressions. These depressions were across the top of the sac - laterally - and were four in number. 'There were also three depressions at the back - horizontally. Sometimes the fly did not seem to gain much in an effort after a relaxation. and at other times the amount of emergence was quite noticeable. When the mouth-parts became visible they were seen to open and the ptilinum to relax simultaneously with each effort. When the fly had nearly emerged the efforts became greater, and the ptilinum sank very much at each relaxation.

After a final struggle the fly crawled slowly out upon the gall and rested. The ptilinum partially collapsed, relieving the fly of its top-heavy appearance, and gradually, and at the same time almost unnoticeably, it was all seemingly absorbed, and a very natural looking fly was before us. We noticed the emergence of a number of these insects, with the same results, as far as we could determine.

The disappearance of the ptilinum at the final stage was almost a mystery. It would seem to be gradually disappearing, and yet, all at once, it was gone and there was not the slightest trace of it. Perhaps a stronger microscope would have revealed more.

We opened some of the galls before the flies emerged to see how heavy a door they had to open. We found the pupa in a small excavation at the centre of the gall, and a circular channel, less than two millimeters in diameter, leading from it to the outside of the gall, only the mere skin of the enlarged stem serving as a covering. 